\title{
Airway management strategies in patients with halo vest fixation devices
}

\author{
Mohammad El-Orbany, MD
}

Received: 15 March 2015/Accepted: 10 April 2015/Published online: 25 April 2015

(c) Canadian Anesthesiologists' Society 2015

\section{To the Editor,}

White et al. ${ }^{1}$ highlighted the airway management challenges in patients with halo vest fixation devices (HVFDs). Limited mouth opening, reduction in the oropharyngeal space due to immobilization in flexion, limited access to the airway due to the physical presence of the device, and the inability to extend the patient's head at the atlanto-occipital joint may all lead to an extremely difficult or impossible airway management situation. Although awake fibreoptic intubation (AFI) has typically been recommended as the technique of choice in this particular situation, the article illustrated that it should not be assumed that AFI is a completely safe and complicationfree technique that always ends in successful intubation. This is simply because such a technique does not exist. McGuire and el-Beheiry ${ }^{2}$ reported two cases of complete airway obstruction during attempted AFI in patients with unstable cervical spine fractures. Face mask ventilation was not possible and, in both cases, an emergency surgical airway was performed to save the patients. The authors concluded that complete obstruction was caused by laryngospasm due to both inadequate topicalization and oversedation. Similarly, Shaw et $a .^{3}{ }^{3}$ reported complete airway obstruction during an attempted AFI when the local anesthetic was sprayed into the upper airway. In addition, Sato $e t ~ a l .{ }^{4}$ reported a similar incidence in a patient with

This letter is accompanied by a reply. Please see Can J Anesth 2015; 62: this issue.

M. El-Orbany, MD ( $\square)$

Medical College of Wisconsin, Milwaukee, WI, USA

e-mail: elorbany2000@yahoo.com rheumatoid arthritis in whom the obstruction resolved after inducing general anesthesia. Several other airway management techniques were successfully used in patients with HVFDs. A few examples of such techniques include induction of general anesthesia and laryngeal mask insertion (with or without fibreoptic tracheal intubation), tracheal intubation using an airway scope or a video laryngoscope, and direct laryngoscopy with manual in-line stabilization. ${ }^{5}$ Induction of general anesthesia, however, carries the risk of airway loss. Furthermore, the degree of mouth opening and the limited space to maneuver or insert an airway device can limit the usefulness of these devices. In some cases, an elective awake tracheostomy may be the safest initial approach to establish a definitive airway. Regardless of the technique, the real challenge should not be forgotten, namely, to establish the airway without causing further neurologic deterioration. White et al. ${ }^{1}$ reported no neurologic deficits after releasing the HVFD and using a video laryngoscope with manual in-line neck stabilization for tracheal intubation. Their finding may pave the way for future large-scale studies to compare the safety, success rate, and incidence of life-threatening and neurologic complications that may be associated with each individual technique.

Conflicts of interest None declared.

\section{References}

1. White AN, Wong DT, Goldstein CL, Wong J. Cervical spine overflexion in a halo orthosis contributes to complete upper airway obstruction during awake bronchoscopic intubation: a case report. Can J Anesth 2015; 62: 289-93. 
2. McGuire $G$, el-Beheiry $H$. Complete upper airway obstruction during awake fibreoptic intubation in patients with unstable cervical spine fractures. Can J Anesth 1999; 46: 176-8.

3. Shaw IC, Welchew EA, Harrison BJ, Michael S. Complete airway obstruction during awake fibreoptic intubation. Anaesthesia 1997; 52: $582-5$.
4. Sato S, Asai T, Hashimoto Y, Okuda Y. Airway obstruction during attempts at fiberoptic intubation in an awake patient (Japanese). Masui 2014; 63: 548-51.

5. Austin N, Krishnamoorthy $V$, Dagal A. Airway management in cervical spine injury. Int J Crit Illn Inj Sci 2014; 4: 50-6. 